\title{
BINGE EATING DISORDERS; UPDATED AND EMERGING APPROACHES
}

\author{
MAHMOUD TEAIMA ${ }^{1 *}$, MAGDI M. ABDEL HAMID ${ }^{2}$, NABIL A. SHOMAN ${ }^{2}$, BHASKARA R. JASTI ${ }^{3}$, MOHAMED A. EL- \\ NABARAWI ${ }^{1}$, MOHAMED YASSER ${ }^{4}$
}

${ }^{1}$ Department of Pharmaceutics and Industrial Pharmacy, Faculty of Pharmacy, Cairo University, Cairo, Egypt, ${ }^{2}$ Department of Pharmaceutics and Industrial Pharmacy, Faculty of Pharmacy, Ahram Canadian University, Giza, Egypt, ${ }^{3}$ Department of Pharmaceutics and Medicinal Chemistry, Thomas J. Long School of Pharmacy and Health Sciences, University of the Pacific, Stockton, USA, ${ }^{4}$ Department of Pharmaceutics and Industrial Pharmacy, Faculty of Pharmacy, Horus University, New Damietta, Egypt

Email: mahmoud.teaima@pharma.cu.edu.eg

Received: 09 Nov 2020, Revised and Accepted: 25 Jan 2021

\section{ABSTRACT}

Objective: Binge eating disorders (BED) recently become a global health care issue for clinicians with detrimental effects on all organ systems. A multidisciplinary strategy including pharmacotherapy is required for its management.

Methods: This review is intended to comparatively evaluate the relative efficacy of different pharmacological agents in BED treatment with new therapeutic approaches, focusing on the clinical evidence and on Phase III randomized controlled trials.

Results: Data suggest that certain treatments have advantages over placebos to reduce binge eating features; however, the small duration of such research with the lack of adequately sized trials was the major limitation in interpreting these findings. Furthermore, these medications are mostly not greatly efficient for BED associated with obesity except for topiramate, which markedly improves the features of binge episodes with weight loss. Till now, lisdexamfetamine is still the only drug with regulatory permission for BED therapy; however, its weight loss efficacy has not been established.

Conclusion: Drugs alone or in combination approaches may be useful pharmacotherapies to yield promising outcomes acutely and over longerterm follow-up in the treatment of BED.

Keywords: Binge eating disorder, Obesity, Binge-episodes, Pharmacotherapy, Lisdexamfetamine

(C) 2021 The Authors. Published by Innovare Academic Sciences Pvt Ltd. This is an open access article under the CC BY license (https://creativecommons.org/licenses/by/4.0/) DOI: https://dx.doi.org/10.22159/ijap.2021v13i2.40214. Journal homepage: https://innovareacademics.in/journals/index.php/ijap

\section{INTRODUCTION}

The Diagnostic and Statistical Manual of Mental Disorders, fifth edition, (DSM-V) considered binge eating disorder (BED) as a distinct diagnosis of eating disorder [1]. BED is described by repeated binge-eating episodes, consuming within a short time $(<2 \mathrm{~h})$ unusually large quantities of food. The individual experiences marked distress and excessive control loss of binge eating without compensatory behaviors of weight loss (such as abuse of diuretics or laxatives, inducing vomiting, intense exercise) characterizing bulimia nervosa [2]. Studies propose that episodes of binge eating in BED may be lower than in bulimia nervosa [3]. The marked distress needed for the determination involves a disagreeable emotional state through the binge episodes, along with fears regarding the continuing effects on body weight and shape. The length of an episode can differ significantly, and many individuals have difficulty separating binge eating into discrete episodes. However, they generally display some challenges in remembering if binge eating occurs on a specified day or not. It is therefore recommended that the frequency of binge days, not just binge episodes, should be assessed, as in bulimia nervosa diagnosis [4].

The DSM-IV stated that the average incidence of binge eating episodes over the previous 6 mo was at least $2 \mathrm{~d}$ a week; in DSM-V, this was changed to at least once a week for 3 mo. Regarding the DSM-V standards, determination of BED is stated if frequent episodes of binge eating involve not less than three features: eat more quickly than usual, eat until uncomfortably complete, eat much food without feeling hungry, eat alone because of emotions of embarrassment, feel disgusted, embarrassed, or depressed as a result of overeating. Also, the DSM-V defined the least severity grade relative to the frequency of weekly binge episodes (mild, 1-3; moderate, 4-7; severe, 8-13; and extreme, $\geq 14$ wly episodes) so that severity degree may also be useful for reflecting the impairment of other functions $[5,6]$.

BED is one of the prominent eating disorders in the United States and worldwide [7] that has the highest incidence in adolescence [8].
Also, BED is more prevalent in women, related to concerns about thinness and shape [9]. Clinical trials indicate that altering concentrations of both estrogen and progesterone are probable to add the risk of BED and probably its prevalence in women [10], in addition to, stress as a potential ovarian hormone moderator that affects binge eating in females $[11,12]$.

Overall, the episodes of BED are related to increased eating disorder (eg, weight gain and shape concern) and general psychopathology (eg, depressiveness, anxiety), and highly comorbid with mood disorders (49\%), anxiety disorders $(41 \%)$, and substance abuse disorders $(22 \%)$ that definitely affects the quality of life and health of an individual [13]. In addition, The BED recurrently cooccurs with attention-deficit/hyperactivity disorder [14] and is accompanied by chronic illnesses such as diabetes, hypertension, and hyperlipidemia; therefore, BED displays similar psychological impairments as the other well-defined eating disorders [15]. BED appears to be more common as the obesity grade rises and is linked with risk factors that increase the chance of weight gain (with body mass index, $B M I \geq 30.0 \mathrm{~kg} / \mathrm{m}^{2}$ ). Obese individuals with BED have a fear of negative evaluation, less self-confidence and more prone to depression than obese patients without BED [16]. BED patients are more vulnerable to the report of dietary disinhibition, unnecessary shape and weight concerns, and difficulty in interpreting hunger and satiety-related visceral sensations. In addition, they are more probable to become overweight at a younger age than obese people without BED, begin diet at a younger age and spend more time on unsuccessful efforts to weight loss. Overweight people with BED feel more overweight and fatter than others with similar weight [17].

\section{Survey methodology}

Three electronic databases (PubMed, Science Direct, and Google Scholar) have been systematically searched for published Englishlanguage articles in all periods up to September 2019. We used terms related to "binge episodes", "binge eating disorder", "bulimia nervosa", "obesity", "pharmacotherapy", "antidepressants", 
"anticonvulsants", "antiobesity", "anorectic", "antiaddiction drugs", "opioid antagonists", "Attention deficit hyperactivity disorder (ADHD)" and individual medications (eg. "lisdexamfetamine (LDX)", "atomoxetine", "topiramate", "lamotrigine", "methylphenidate", "acamprosate", "naltrexone", "d-fenfluramine", "liraglutide", "chromium", "baclofen", and "vortioxetine"). Relevant articles were then screened for references of this review.

\section{Pharmacological treatment}

The first therapeutic approaches for BED were obtained from bulimia nervosa or various research on the therapy of obesity and depression. When various studies revealed significant variations in psychopathology, consideration of a definite treatment strategy has become clear [18]. The treatment of BED is multidimensional, so a number of pharmacological and psychological strategies have been designed and evaluated in diverse studies [19]. This paper provides the rationale of the main pharmacological treatments administered alone or in combinations for patients with BED and reviews their effectiveness according to the previous clinical findings with patients had BED.

The use of pharmacotherapy to treat BED has several reasons. Like other psychiatric condition, as depression, anxiety, and personality disorders, as well as substance abuse, BED is a mental case with hereditary and neurobiological disorder causing distress, and dysfunction and does not always react sufficiently to current psychological therapy [20]. The more we learn about eating behavior, and diagnosis of eating disorder, neuroimaging work widely explains the neurobiology of binge eating [21]. Animal binge eating models show the impact of dopamine, norepinephrine, and opioid systems, all influencing eating behavior [22]. A behavioral study has proposed a critical function for the serotonin system, as mice that lack $5 \mathrm{HT}_{2 \mathrm{C}}$ functional receptors show noticeable hyperphagia, leading to obesity progression [23]. Also, animal findings display that BED is concomitant with changes in the gastrointestinal tract. For example, repeated gastric distensions alter the intake of food and neuroendocrine profiles in rats [24]. Additionally, many treatments available affects variable neurotransmitter systems implicated in appetite or weight management, which can have beneficial effects on BED treatment

This review article currently summarizes and compares the different drug classes used for the treatment of BED based on their pharmacological rationales.

\section{Antidepressants}

Antidepressants were among the first medications assessed for BED treatment. BED mostly come with other depressive and anxiety disorders. It remains questionable whether the improvements achieved with antidepressants are associated principally with improvement in BED outcomes or concomitant mood or anxiety features. Also, BED may be linked to abnormalities in neurotransmitter systems including serotonin, norepinephrine and dopamine which most antidepressants target [20].

\section{Selective serotonin reuptake inhibitors (SSRIs)}

There has been an inverse relationship between serotonin levels and food consumption, where a selective serotonin decrease is related to hyperphagia and consequent weight gain; alternatively, lowering the consumption of food generally leads to increased serotonin circulation. The most commonly used SSRIs are fluoxetine, fluvoxamine, sertraline, citalopram, and escitalopram. Several clinical studies assessed their efficacy in BED therapy regarding decreases in weight, the frequency of binge episodes, and binge days [25].

Fluoxetine is the only official drug allowed for bulimia nervosa therapy by the Food and Drug Administration (FDA) and can reduce food intake and body weight [26]. In 1996, the first randomized controlled double-blind study was designed to assess fluoxetine efficacy for $6 \mathrm{~d}$ [27]. A sample of 79 overweight women (38 of them had BED) with a BMI (30-45 $\mathrm{kg} / \mathrm{m}^{2}$ ) received flexible doses of fluoxetine (up to $60 \mathrm{mg} / \mathrm{d}$ ). This was accompanied by a significant reduction in caloric consumption of around $600 \mathrm{kcal} / \mathrm{d}(\mathrm{p}<0.007)$ while the of binge eating frequency did not reduce significantly $(\mathrm{P}<0.45)$. A 6-week, randomized, controlled trial conducted on 60 obese patients with BED showed similar findings [28]. The study showed that fluoxetine daily doses of 20 to $80 \mathrm{mg}$ were well tolerated and significantly reduce the binge-eating frequency, body weight, BMI, and severity of disease along with relieving depressive symptoms. However, another randomized 16-week double-blind study that compared the efficacy of fluoxetine and cognitivebehavioral therapy (CBT) did not confirm the findings of these two studies [29]. Fluoxetine (60 mg/day), CBT plus fluoxetine, CBT plus placebo, or placebo were randomly assigned to 108 patients with BED. CBT exhibited efficacy for binge eating remission rates, cognitive and psychological symptoms when added to fluoxetine or placebo. Additionally, the combination of fluoxetine plus CBT showed no superiority over CBT alone. These findings were also established by another study conducted on 116 patients with BED who received behavioral weight control therapy [30]. Patients randomly received adjunctive CBT or no CBT and to fluoxetine or placebo for $20 \mathrm{w}$. However, fluoxetine $(40-80 \mathrm{mg} / \mathrm{d})$ showed efficiency in decreasing depressive features.

An open-pilot 9-week study involving 5 BED patients proposed the effectiveness of fluvoxamine in BED therapy [31]. The administration of fluvoxamine at a daily dose (100 to $200 \mathrm{mg}$ ) was related to decrease in binge eating frequency, weight loss, and anxiety level. A randomized, controlled, double-blind trial involving 85 obese patients with BED established later these findings of fluvoxamine at a daily dose (50-300 $\mathrm{mg}$ for $9 \mathrm{w}$ ) [32]. But there was a practical limitation in both studies such as insignificant sample size and short trial period. In addition, a randomized, controlled, doubleblind study lasting $12 \mathrm{w}$ doubts the promising outcomes of the previous research [33]. The study showed that fluvoxamine (150 $\mathrm{mg} /$ day) had the same efficacy of placebo in the binge eating frequency, weight changes, and improvement in depressive symptoms.

A 6-week, randomized, controlled, double-blind study assessed sertraline (50-200 mg/day) on 34 obese participants with BED [34]. Sertraline had advantages over placebo for reducing binge episodes frequency, the severity of disease $(p<0.001)$ and BMI $(p=0.002)$. These results were in line with a 12-week, randomized, parallelgroup, controlled study, in which a sample of 20 bulimic patients received daily sertraline $(100 \mathrm{mg})$ [35]. There was a significant reduction in the binge episodes frequency and weight change after 2 w. A third study was conducted on 32 obese patients (14 diagnosed with BED and 18 with a Binge Eating Scale (BES) high score, but not meeting the BED criteria) who received sertraline treatment (100 to $200 \mathrm{mg} /$ day for $24 \mathrm{w}$ ) [36]. After a 5-week follow-up, sertraline significantly decreased body weight and the frequency of weekly binge episodes with a significant improvement $(\mathrm{p}<0.002)$ in BES score. A randomized, double-blind, controlled study evaluating sertraline and fluoxetine in forty-two females with BED and obesity was performed. Twenty-two females were treated daily with sertraline (100-200 mg) and the other twenty with fluoxetine (40$80 \mathrm{mg}$ ) for 6-month treatment [37]. The study showed the positive impacts of continuous SSRI treatment on patients who initially responded to SSRIs for up to 6 mo with reduced binge eating episodes and weight loss.

The first randomized, controlled study evaluating the tolerability and effectiveness of citalopram in BED treatment involved 38 patients who received daily for $6 \mathrm{w}$ citalopram dose (20 to $60 \mathrm{mg}$ ) or a placebo [38]. The study showed significant superiority of citalopram for decreasing weekly binge eating frequency, BMI, and body weight.

A 12-week, randomized placebo-controlled trial evaluated the efficacy of escitalopram in 44 obese participants with BED [39]. Escitalopram (up to $30 \mathrm{mg} /$ day) was useful for weight loss, with a significant BMI reduction ( $p=0.048)$, and global severity of illness scores $(p=0.026)$ but was not efficacious in reducing the binge episodes frequency, weekly binge days, and obsessive-compulsive symptoms.

Vortioxetine is a novel atypical antidepressant that received the FDA approval for the major depressive disorder treatment in 2013. Vortioxetine enhance serotonin levels via a dual mechanism of action as serotonin reuptake inhibitors and serotonin modulators. 
Vortioxetine also increases in certain areas the levels of noradrenaline, dopamine, and acetylcholine, along with modulating neurotransmission of $\gamma$-aminobutyric acid and glutamate [40, 41]. Furthermore, vortioxetine seems to have the potential for cognitive enhancement, which may have benefits in disorders characterized by executive dyscontrol. This proposes that drug could alleviate the BED symptoms by complementary pathways [42]. The efficacy of vortioxetine in BED treatment was evaluated by a 12-week, doubleblind, controlled study. Eighty adult patients with BED randomly assigned in a parallel design to vortioxetine $(10 \mathrm{mg} /$ day for the first week, then up to $20 \mathrm{mg} /$ day) and placebo. Vortioxetine was not superior to placebo in reducing the binge-eating frequency, weight, and BMI with a good tolerability profile. So, further trials needed to evaluate its efficacy in BED treatment [43].

\section{Serotonin and norepinephrine reuptake inhibitors (SNRIs)}

The drugs including duloxetine, and venlafaxine appeared to have a synergetic effect in BED therapy by having dual actions inhibiting reuptake of both 5-HT and NE [44].

Two case reports indicated that duloxetine was significant in the refractory BED therapy, which suggested that nausea and reduced appetite would be helpful in the treatment $[45,46]$. A 12-week open study showed the efficacy of duloxetine at a flexible daily dose $(60$ $120 \mathrm{mg}$ ) in 45 obese patients with BED or subthreshold BED symptoms [47]. Duloxetine significantly reduced weight, BMI and disease severity, as well as improved depressive symptoms. Similar results were observed in a randomized, 12-week, double-blind, controlled study involving 40 depressed participants with BED [48]. Duloxetine (30-120 mg/day) significantly reduced the frequency of binge episodes, binge days, and body weight, besides a significant relief $(p=0.01)$ in depressive disorder score.

On the other hand, there was only one retrospective trial conducted on 35 overweight or obese patients with BED [49]. The superior effect of venlafaxine (75-300 mg/day for 120 d) to placebo was recorded in decreasing weight, BMI $(\mathrm{p}=0.02)$, and severity of illness, without significant reduction in binge episodes $(p=0.08)$.

\section{Norepinephrine reuptake inhibitors}

In 12-week open trial, the effectiveness and safety of reboxetine at a daily dose ( $8 \mathrm{mg}$ ) were evaluated on 9 obese subjects with BED [50]. Five patients experienced significant improvements in the frequency of binge eating and general quality of life. There was also a statistically significant reduction in Mean BES scores $(p=0.0003)$ and BMI $(\mathrm{p}=0.01)$ with no serious adverse events.

\section{Norepinephrine-dopamine reuptake inhibitors}

Multiple studies revealed that bupropion able to improve hyperphagic depressed individuals and overweight or obese patients with depression [51-55]. The efficacy of bupropion and sertraline in the treatment of BED and comorbid depression was comparably evaluated in a 24-week retrospective cohort study [56]. The study involved 15 patients who received bupropion (150 mg per day) and the other 15 received sertraline (200 mg per day). During the first $6 \mathrm{w}$ of treatment, bupropion and sertraline had similar efficacy in improving weight loss, however, after completion of the study period, bupropion showed a superior improvement in promoting weight loss $(5.5 \pm 3.6 \mathrm{~kg})$ and was proportional to BMI which was not the case with the sertraline group who had $1.9 \pm 1.2 \mathrm{~kg}$ weight reduction. On the other hand, bupropion and sertraline had similar advantages in improving depression features and reducing the frequency of binge eating with the same tolerability profile. At week 24 , patients who received bupropion showed a $75 \%$ reduction of weekly binges compared to $72 \%$ in the sertraline group. A complete binges remission was also recorded for $53 \%$ of the bupropion group at week 24 versus 33\% for the sertraline group.

Another randomized, 8-week, double-blind, controlled study involved 61 depressed, obese females with BED who received bupropion (300 mg/day) [57]. The short-term results showed bupropion with a significant BMI reduction $(p=0.002)$ but the frequency of binge episodes, food cravings, and depressive features was not improved significantly. These results may refer to the lower bupropion dosing for short period comparing to the previous studies. Currently, combinations of bupropion with other treatments are investigated for the therapy of BED and comorbid obesity $[58,59]$.

\section{Tricyclic antidepressants (TCAs)}

Tricyclic antidepressants were conflicting about reducing binge episodes frequency and body weight [20]. Among TCAs, the efficacy of imipramine at a low dose $(75 \mathrm{mg} /$ day) was assessed in an 8-week, randomized, double-blind, controlled study, following a 6month open extension phase [60]. The trial was conducted on a sample of 31 obese binge eaters. It was significantly effective to add imipramine to dietary counseling with psychological support in reducing binge episodes, and body weight along with improving depressed mood $(p=0.02)$ as assessed by the Hamilton Scale for Depression. Of interest, the beneficial effect was maintained by patients receiving imipramine for $26 \mathrm{w}$ after treatment.

\section{Anticonvulsants (GABAergic and glutamatergic modulators)}

Anticonvulsant drugs appeared to have a beneficial impact on the treatment of bipolar disorder and impulse-control disorders, which is associated with their potential effect in BED therapy [61]. Anticonvulsants, administered alone or in combination therapy, showed efficacy in the treatment of BED and obesity for their significant anorectic effect [62]. Anticonvulsants affect the system of neurotransmitters or peptides that regulate eating behavior. However, Drugs such as Phenytoin, valproate, and carbamazepine may be promptly abandoned due to their ability to increase appetite and weight which may counteract their beneficial effect [63].

Topiramate is a sulfamate-substituted monosaccharide which is officially permitted in epilepsy therapy and prophylaxis of migraine. Topiramate, due to inhibition of the excitatory glutamate pathway in the lateral hypothalamus, might have a specific effect on appetite suppression and recovery of overeating control. Topiramate use in BED patients significantly reduces the frequency of binge episodes and body weight but cognitive impairment makes it hard to tolerate [64]. A 14-week, randomized, double-blind, placebo-controlled study on 61 obese subjects with BED assessed the efficacy of topiramate (25-600 mg/day) [65]. Topiramate was significantly effective in reducing the frequency of binge episodes, weekly binge days, body weight (mean-5.9 kg), and BMI ( $\mathrm{p}=0.003)$. Also, Topiramate showed a significant improvement in the severity of disease ( $p$ $=0.02$ ) and the score of Yale-Brown Obsessive-Compulsive Scale $(\mathrm{p}=0.004)$ as a measure of the compulsive eating behaviors. However, topiramate was not significantly $(p=0.28)$ effective in improving depressive features as assessed by HRSD. The same research group evaluate the long-term efficacy and tolerability of topiramate in the 42 -week open extension phase of the previous trial including the completers $(n=35)$ [66]. The findings revealed that there was an enduring improvement in the treatment of BED with obesity over the long term but was also related to a high discontinuation rate. Similar results were established over a longer period in a 16-week RCT involving a larger sample of 394 obese patients with BED [67]. Topiramate showed a significant (all $p$ values $<0.001$ ) decrease in the frequency of binge episodes, weekly binge days, body weight, BMI and severity of illness.

A 21-week, double-blind, randomized, placebo-controlled study of 73 obese participants with BED evaluated the efficacy of topiramate in conjunction with CBT [68]. Patients received 19 CBT sessions combined with $206 \pm 36 \mathrm{mg}$ /day of topiramate $(\mathrm{n}=37$ ) or placebo (n $=3619$ ). Both treatments significantly reduced the frequency of binge episodes. However, addition topiramate to CBT topiramate had advantages over placebo for significantly reducing body weight $(\mathrm{P}<0.001)$. The study showed the treatments did not differ significantly in reducing the frequency of binge episodes, BES and Beck Depression Inventory scores. The authors concluded that topiramate in conjugation with CBT enhanced the efficacy of the latter for BED therapy, improving short-term binge remission and weight loss. To end, Topiramate was also hypothesized to be effective in people who had undergone gastric banding surgery. It showed the ability for further weight loss in bariatric surgery patients $[69,70]$. 
Zonisamide is a second-generation anticonvulsant medication with a diverse mechanism of actions, including blockade of voltage-gated sodium and T-type calcium channels, reduced glutamatergic transmission by blocking the potassium-evoked glutamate release, and being carbonic anhydrase inhibitor. Interestingly, weight loss was stated as a comparatively prevalent side effect in people who contributed to zonisamide clinical trials as an anticonvulsant. In an open-label prospective trial, flexible daily dose of zonisamide dose (100 to $600 \mathrm{mg}$ ) significantly reduced binge eating frequency and body weight when administered to 15 BED patients [71]. In a larger randomized 16-week, placebo-controlled, double-blind trial $(n=60)$, the effectiveness of the same dose of zonisamide was again investigated [72]. Zonisamide capable of significantly decreasing the binge eating frequency, body weight, and severity of disease $(\mathrm{p}<0.001)$. However, the medication showed poor tolerability due to upset adverse events (eg. ataxia, fatigue, difficulty with memory, anorexia). Also, zonisamide can be combined with CBT in BED patients for reducing weight and binge eating frequency, with maintaining results $1 \mathrm{y}$ after the treatment ends [73].

Finally, it was suggested that lamotrigine decrease binge eating by inhibiting the release of presynaptic glutamate as glutamatergic stimulation of the lateral hypothalamus results in higher food consumption. The efficacy of lamotrigine in BED therapy was assessed in a randomized, double-blind, placebo-controlled trial on 51 obese. Lamotrigine daily dose (236 mg) for $16 \mathrm{w}$ significantly reduced the fasting levels of glucose, insulin, and triglycerides and a greater weight loss than placebo. However, the frequency of weekly binge episodes and binge days was comparable [74].

\section{Anti-obesity medications}

BED is concomitant with high comorbidity of overweight and obesity. Also, Anti-obesity drugs can have anti-binge eating functions, either directly by suppressing appetite or indirectly by metabolic effects to increase the satiety threshold. Clinical trials were conducted to evaluate the efficiency of such treatments to promote weight loss with improving BED-typical symptoms.

Sibutramine is an inhibitor for noradrenaline and serotonin reuptake and, to a lower extent, dopamine and is authorized for obesity therapy by the FDA [75]. Sibutramine could promote and maintain weight loss by stimulating satiety and the thermogenesis in obese patients with BED. Besides, its efficacy in enhancing psychopathology related to eating (reduction in weekly binge days) and self-reported depression scores in BED patients. However, this drug has limited use because of the high risk of serious cardiovascular and cerebrovascular problems found in overweight or obese patients with pre-existing cardiovascular dysfunction [76]. Three randomized double-blind case-control studies have done to evaluate sibutramine efficacy in BED treatment. The first study was conducted in sixty obese patients with BED received $15 \mathrm{mg}$ daily dose of sibutramine or a placebo for 12-week [77]. Another 12-week study included 20 obese females with BED who received sibutramine at a daily dose of $10 \mathrm{mg}$ [78]. The third study involved largest sample size $(\mathrm{n}=304)$ who received sibutramine $(15 \mathrm{mg} /$ day $)$ for a longer period (24-week) [79]. Sibutramine in all these studies significantly decreased the frequency of binge episodes, binge days, and BMI accompanied with improving depressive features.

Orlistat is officially allowed by the FDA as an anti-obesity drug as a potent pancreatic and gastric lipases inhibitor that works locally in the gut lumen with minimal absorption [80]. The research showed that orlistat is effective in binge eating control in obese people, despite lacking the central nervous system activity. In terms of eating disorder psychopathology and psychological distress, there have been considerable and similar improvements in orlistat and placebo recipients [81]. A 24-week, randomized, double-blind, controlled study reinforced the ability of orlistat monotherapy for promoting weight loss and metabolic parameters. Eighty-nine obese patients with BED received $120 \mathrm{mg}$ orlistat three times per day in combination with a hypocaloric diet [82]. Another two randomized, placebo-controlled trials assessed the efficacy of orlistat $(120 \mathrm{mg}$ three times daily) administered with CBT [83] or behavioral weight loss (BWL) [84] in the obese patients with BED. In the first trial, significant intent-to-treat remission rates for binge episodes were associated with adding orlistat to CBT for $12 \mathrm{w}$, but not at the 3 mo of follow-up [83]. However, a significant weight loss was detected with adding orlistat to CBT both after therapy and after 3-month follow-up. The addition of orlistat or placebo to CBT had the same efficacy in increasing psychopathological eating disorders induced by BED after treatment and 3-month follow-up. The second trial was performed on 79 obese patients with or without BED. Addition of orlistat to BWL was not significantly better than the addition of placebo in the BED group to improve BMI, binge eating or depressive symptoms. However, the addition of orlistat to BWL resulted in more weight loss than the addition of placebo in obese patients without BED but not with BED patients [84].

Phentermine is the most widely prescribed anti-obesity medication allowed for short-term treatment. Phentermine is a sympathomimetic amine that may reduce appetite by stimulating norepinephrine release. Phentermine is currently evaluated in combinations with topiramate in BED therapy for its efficacy in weight loss $[85,62]$. A double-blind, randomized study considering the effectiveness and safety of extended-release of phentermine/topiramate $(3.75 / 23 \mathrm{mg}-15 / 92 \mathrm{mg})$ in BED was investigated on 15 participants for $12 \mathrm{w}$ [86]. Additionally, a prospective open trial assessed the efficacy of phenterminetopiramate extended-release ( 6.8 to $41.4 \mathrm{mg} /$ day) for $12 \mathrm{w}$ including ten obese or overweighed individuals with BED [87]. The combination treatment significantly reduced weight, BMI, binge eating frequency, clinical severity scores and obsessive-compulsive outcomes. However, no long-term studies are available, and it is not known if the weight loss persists and how many individuals relapse back into obesity.

Moreover, D-Fenfluramine was appeared to be effective in BED treatment due to its serotoninergic action that mediates satiety and causes both food consumption and body weight to decrease as well as, a powerful serotonin reuptake inhibitor and serotonin releaser of its metabolite d-norfenfluramine [88]. An 8-week, randomized, double-blind, controlled trial evaluated the potency of dfenfluramine up to $30 \mathrm{mg}$ /day in 28 obese females with BED [89]. There was a significant decrease in the frequency of binge episodes; however, Binge episodes returned to the level of pretreatment 4 mo after therapy ended. Studies were stopped and d-fenfluramine was no longer available on the world market due to concerns about cardiac valve defects and lung hypertension [90].

Liraglutide is a glucagon-like analog peptide used in diabetes type 2 . Liraglutide is appeared to be capable of significantly reducing weight [91] and maintaining weight [92]. Forty-four obese patients with BED received diet and exercise counseling then were randomized with liraglutide (1.8 mg) or placebo in a 12-week double-blind controlled pilot trial [93]. Liraglutide treatment significantly improved binge eating symptoms evaluated via BES score and weight loss. This was accompanied by significant reductions in BMI $(\mathrm{p}<0.001)$, waist circumference $(\mathrm{p}<0.004)$, systolic blood pressure $(\mathrm{p}<0.042)$, fasting glucose $(\mathrm{p}=0.027)$, and total cholesterol ( $\mathrm{p}$ $=0.044)$. It is noteworthy that $81 \%$ of liraglutide patients have shifted from binge eating to non-binge eating. Recently, a case report revealed the effectiveness of liraglutide in a male with compulsive food-related behavior associated with autism. The male patient was initiated with a daily dose of $0.6 \mathrm{mg}$ and steadily up to $2.4 \mathrm{mg}$ over the following $8 \mathrm{w}$. Treatment with liraglutide revealed immediate positive response in the patient's manifesting by preventing foodrelated repetitive thoughts and compulsive eating. There was also a significant reduction in the patient's weight after the first week of therapy [94].

\section{Attention deficit hyperactivity disorder (ADHD) medications}

Most medications used in ADHD treatment modulates dopaminergic and norepinephrine circuits, which are linked to the control of feeding behavior and reward system along with the binge eating biology. These medications demonstrated an anorectic and weight loss effect, and preliminary findings indicate that drugs used in ADHD like methylamphetamine and methylphenidate mitigate binge eating features in bulimic individuals [95]. A relationship between BED and ADHD in both adolescents [96] and adults [97] has been shown in available data. Interestingly, the incidence of 
eating disorders in individuals with ADHD is about $12 \%$, while the incidence of ADHD in individuals with eating disorders is estimated at $5 \%$ to $17 \%$ [98].

Atomoxetine is a selective reuptake inhibitor of norepinephrine that showed efficacy in weight loss and reduction of binge episode frequency. In a 10-week, randomized, double-blind, controlled study, atomoxetine (40 to $120 \mathrm{mg} /$ day, $\mathrm{n}=40$ ) showed efficacy in reducing features of binge eating episodes and weight loss [99]. Still, these results should be long-established through larger studies. Atomoxetine administration was accompanied by adverse events such as loss of appetite, upset stomach, insomnia, headache, constipation, and dry mouth [67].

While lisdexamfetamine (LDX) is a d-amphetamine prodrug that blocks the reuptake of dopamine and norepinephrine and enhances their release in the synapse [100]. LDX has been approved in 2015 for moderate and severe BED treatment [101]. However, LDX administration was accompanied by a limitation of use for weight reduction. It is attributed to significant depressive symptoms and severe cardiovascular problems associated with other sympathomimetic medications for weight loss. Several studies established the efficacy of LDX in BED treatment [102-106]. A randomized, double-blind, forced-dose titration controlled study of on 267 participants with BED evaluated the efficacy of LDX. Patients received LDX at daily doses of 30,50 , or $70 \mathrm{mg}$ or placebo. Over $3 \mathrm{w}$, LDX dosages were titrated $20 \mathrm{mg} /$ week and remained unchanged for the next $8 \mathrm{w}$. The results presented the optimal dosage of oral LDX in reducing binge episodes and binge days at both 50 and 70 $\mathrm{mg} /$ day, but not at $30 \mathrm{mg} /$ day [102]. The same researchers evaluated the effectiveness and safety of LDX in two 12-week randomized, double-blind, controlled trials. A sample of 383 patients participated in the first trial, while 390 patients were engaged in the second. Patients received placebo or LDX (50 or $70 \mathrm{~g} /$ day) in the first $4 \mathrm{w}$, followed by 8-week maintenance [103]. LDX was significantly superior at $1 \mathrm{w}$ and at $12 \mathrm{w}$ in improving weekly binge features, weight loss and binge eating-related secondary measures. Another randomized, double-blind, controlled study of 275 participants who received LDX (50 or $70 \mathrm{mg} /$ day for $6 \mathrm{mo}$ ) supported the previous findings [104]. An open-label extension phase of 604 BED adults assessed the long-term tolerability and safety of LDX for 12 mo [105]. A total of 506 participants reported adverse events: $7 \%$ and $2.8 \%$ experienced serious side effects, respectively as well as $9 \%$ of the participants required to stop therapy while 369 participants completed the study. Dry mouth, vision changes, poor appetite and stomach pain were the most prevalent side effects identified in more than 10 percent of patients. Also, two randomized, double-blind, controlled trials evaluated the 12 -week endpoints related to LDX efficacy. Efficacy measures were improved at $1 \mathrm{w}$, which was maintained in adults with BED throughout the 12-week research [106].

Methylphenidate, a psychomotor stimulant, is a first-line ADHD medication. It acts by binding to the dopamine transporter inhibiting the dopamine reuptake with enhancing synaptic dopamine. A double-blind, controlled crossover trial of 32 participants with BED and 46 healthy age-matched controls exhibited implications for treatment response with methylphenidate [107]. Individuals with BED and have at least one version of dopamine transporter associated with 9-repeat allele experience greater appetite suppression relative to methylphenidate. The findings proposed that an unidentified genetic variant overrepresented in BED intervene dopamine transporter to suppress appetite responding to stimulant administration.

A double-blind, drug-placebo, cross-over study examined gender differences in methylphenidate response to a single dose and evaluated whether BED status moderated the predicted differences. The study was conducted on overweight or obese patients with BED $(\mathrm{n}=90)$ and without BED $(\mathrm{n}=108)$. After oral administration of the drug/placebo, ratings of appetite and food cravings have been evaluated through a laboratory-based snack-food challenge as well as emotional/mood ratings were evaluated every $15 \mathrm{~min}$. Women demonstrated significantly greater sustained responses than their male. Among the women, a significantly greater reduction from the placebo was observed in measures of appetite and food cravings. While the two conditions showed similar outcomes in any of the food-related variables among men [108]. In a 12-week randomized study, the effectiveness of methylphenidate versus CBT has recently been evaluated in BED treatment. The trial conducted on $49 \mathrm{BE}$ women randomly to receive methylphenidate $(n=22)$ or CBT $(n=27)$. Administration of methylphenidate and CBT was accompanied by a significant improvement in binge episodes features and quality of life. However, methylphenidate had a greater impact on BMI reduction compared to CBT [109].

\section{Anti-addiction medications}

The progress into the biological basis of the addictive disorders showed a high comorbidity rates between addiction and eating disorders, such that addicted to highly palatable food contributes to develop and maintain obesity [110]. This is attributed to have comparable diagnosis, characterized by cravings, and feeling of loss of control over addicted substances or food [111]. These findings promote an assumption that addictive disorders and binge eating may share common pathophysiological and psychological cores. For instance, abused drugs and highly palatable food induce the same brain reward circuits and that anti-addiction medications may modulate various neurotransmitter systems such as GABA, dopamine, glutamate, and cannabinoid that comprise this circuitry [112]. These findings above urge the assessment of drugs used for addiction as a potential therapy for BED.

\section{Baclofen}

Baclofen is a GABA agonist and helps to treat alcoholism and addictive substances with cocaine, methamphetamine, nicotine, and heroin [113]. An open-label pilot study was conducted on $4 \mathrm{BE}$ females and 3 bulimic females receiving baclofen ( $60 \mathrm{mg} /$ day) for 10 $\mathrm{w}$ [113]. Baclofen treatment was accompanied by reducing the binge-eating frequency in all participants without serious adverse effects. Five patients (including 3 BED) experienced a significant reduction in the frequency of weekly binge episodes. Also, there were no binge eating episodes in three patients (including 2 BED). These promising results were confirmed in a randomized, doubleblind, controlled, crossover trial involving $12 \mathrm{BE}$ participants. The results were obtained during a run-in period, placebo phase (48 d), and baclofen phase (up to $60 \mathrm{mg} /$ day for $48 \mathrm{~d}$ ). Compared to placebo, the baclofen phase revealed a significant decrease in binge eating frequency with improving depressive symptoms. Baclofen and placebo phases have similar significant reductions in food cravings and binge severity (BES score) [114]. A case series $(n=5)$ stated the efficacy of high-dose baclofen in BED treatment [115]. However, the evidence of these studies is restricted due to small sample size of participants.

\section{Opioid antagonists}

The opioid system was closely associated with the rewarding influence of consuming palatable food. Administration of opioid receptor agonist increases food intake, while opioid receptor antagonist decreases it [116]. Clinical studies suggest that the increased pain threshold in eating disorders patients shows abnormalities in the opiate system that involved in eating behavior, reward, and addiction [117].

Several studies showed the efficacy of the opiate antagonist naltrexone in improving binge features and hunger attacks in obese people due to its role in the dopamine reward circuitry $[118,119]$. In an open-label trial, binge eating and purging behaviors was significantly reduced in bulimic individuals receiving naltrexone (200 to $300 \mathrm{mg}$ ) and this outcome was established at 3 to 5 mo follow-up [120]. The same team research conducted another open-label trial for $6 \mathrm{w}$ on 16 individuals with bulimia nervosa to evaluate naltrexone in either standard (50$100 \mathrm{mg} /$ day) or higher (200-300 mg/day) doses [121]. There was only a significant decrease in of binge-eating frequency related to the elevated doses of naltrexone. It is hypothesized that the difference in response to opioid receptors may be referred to the mechanism of action. Naltrexone is a weak $\kappa$-opioid receptor antagonist associated with eating behaviors; therefore, only the high doses could achieve an adequate receptor blockade. 
Several studies widely investigated the use of naltrexone as part of combination therapies in recent years. One such combination, naltrexone in combination with antidepressant bupropion extendedrelease, is allowed for weight control as an adjuvant to diet and physical activity and they may be more effective in the treatment of BED comorbid with obesity [122]. A randomized, double-blind, controlled, phase 3 trial of 1742 participants showed that sustainedrelease tablets of naltrexone/bupropion combination were significantly superior to placebo in weight loss $(p<0.0001)$ [58]. In another 24-week open-label study, 25 females with moderate to severe BED received the combination of naltrexone ( $32 \mathrm{mg} /$ day) and bupropion (360 mg/day) tablets [59]. A significant improvement in binge severity (BES score) was reported in $83 \%$ of patients at 24 week accompanied by a reduction in symptoms of depression and weight control. Furthermore, a randomized, double-blind, controlled study of 41 overweight binge eaters and 28 normal-weight bulimics investigated the outcome of naltrexone and imipramine in eating disorders. Patients received daily doses of naltrexone (100-150 $\mathrm{mg}$ /day) and imipramine (50-150 mg/day) for $8 \mathrm{w}$. Both medications significantly decreased the duration and frequency of binge episodes in the overweight binge eaters $(P=0.02)$ [123]. Of interest, research progress has presented that targeting reward systems can also select the suppression of certain types of food intakes that are very reinforcing, foods such as fatty or sugary food containing a huge number of calories but with low nutritional value [124]. Based on this hypothesis, baclofen and naltrexone efficacy were assessed in rats with BED, alone or in combination. Combination treatment was superior to either medication alone in effectively reducing excessive consumption of fatty or sugary foods related to binge eating $[125,126]$. Furthermore, two case reports outlined the effective combination of fluoxetine with naltrexone (100 mg/day). One case showed decreases in binge symptoms and weight in an elderly female with a history of BED and severe depression upon adding naltrexone to fluoxetine $(60 \mathrm{mg} /$ day $)$, diet, and CBT [127]. The other case was a patient with depression and posttraumatic stress disorder whose both BED and sexual dysfunction remitted with naltrexone [128]. Naloxone is another opioid antagonist that has revealed some favorable effects in BED when administered through intranasal route [129]. Additionally, nalmefene is a new compound combining $\mu$ and $\delta$ receptor antagonist and $\kappa$ receptor partial agonist. The direct contribution of the opioid system in alcohol reward process and the indirect modulation of dopaminergic transmission in the mesolimbic areas are considered the main mechanism of nalmefene action to reduce alcohol intake [130]. In animal models, nalmefene resulted in being more effective than naltrexone, another opioid modulator shown to be effective in BED [131]. A case report also presented the potential use of nalmefene in BED therapy and other food craving disorders [132].

\section{ALKS-33}

ALKS-33 is an alcohol dependence modulator that selectively binds to $\mu, \kappa$, and $\delta$-opioid receptors [133]. In contrast to naltrexone, it is not subjected to first-pass metabolism increasing its oral bioavailability. A 6-week randomized, double-blind, controlled trial assessed the efficacy of ALKS-33 in 62 obese patients with BED [134]. Although ALKS-33 significantly decreased the frequency of weekly binge episodes and weight, the decrease was not significant relative to placebo.

\section{Acamprosate}

Acamprosate is an N-methyl-D-aspartate glutamate receptor antagonist allowed for abstinence maintenance in alcohol dependence $[135,136]$. Along with BED was associated with substance use disorders, various studies proposed that reduced glutamate activity may reduce food intake in binge eating [112]. In a 10 -week, randomized, double-blind trial, 40 participants received the placebo or acamprosate (2,997 mg daily) [137]. Although acamprosate did not significantly reduce the frequency of binge episodes or any other findings in the longitudinal analysis, a significant improvement was observed in frequency of binge-eating days and psychopathological of obsessive-compulsiveness outcomes, and quality of life in the secondary endpoint analysis.

\section{Other drugs}

\section{Memantine}

Memantine is a nootropic glutamate-modulating drug that in two small open-label trials appeared to decrease the frequency of binge episodes in BED. In the first, five obese women with BED were treated in the morning with memantine $(10 \mathrm{mg})$ and late evening with memantine (10-20 mg) with weight loss (1.2 kg/week) [138]. In the second, 16 participants received for $12 \mathrm{w}$ memantine (5 to 20 $\mathrm{mg} /$ day) [139]. Memantine significantly decreased binge eating frequency with improving the severity of illness, although it did not significantly reduce body weight and BMI.

\section{Sodium oxybate}

Sodium oxybate, $\gamma$-hydroxybutyrate sodium salt, is allowed in patients with narcolepsy for the therapy of excessive daytime sleepiness and cataplexy [140]. The efficacy of sodium oxybate in BED treatment may be attributed to several rationals. $\gamma-$ hydroxybutyrate. The drug modulates a number of neurotransmitters such as GABA, dopamine, serotonin, opioids, and glutamate involved in feeding behaviors [141]. Patients with narcolepsy also experienced weight loss after receiving sodium oxybate treatment. Moreover, $\gamma$-hydroxybutyrate was associated with suppression of alcohol cravings and thus decreasing alcohol consumption in patients with alcohol overuse disorders. The ability to manage drug cravings and abuse may also be linked to suppress aspects of excess feeding behaviors food cravings, in view of the common association between addictive disorders and BED. There was only an open-label trial of 12 participants with BED evaluating the efficiency of sodium oxybate for $16 \mathrm{w}$ in BED treatment [142]. Ten participants finished at least one post-baseline assessment, and five finished the trial due to the absence of efficacy, side effects, or other reasons for losing follow-up. Sodium oxybate significantly reduced the frequency of binge episodes, binge days, and body weight as well as improving symptoms of obsessive compulsion.

\section{Chromium picolinate}

Chromium is a vital mineral improving the regulation of mood, appetite, and glucose. Chromium directly enhances insulin [143] and serotonin functioning [144] and may also be downstream effectors of signaling pathways modulated by dopamine. These neurotransmitters have similar pathway of protein kinase that related to food consumption and homeostatic control of energy [145], rendering it a possible candidate for treating BED with comorbid depressive symptoms. In a 6-month, randomized, double-blind pilot trial, 24 overweight adults with BED received one of three treatments: placebo $(n=7)$ or chromium at higher doses (1000 mcg daily, $\mathrm{n}=8$ ) or chromium at moderate doses (600 mcg daily, $n=9$ ) [146]. No confirmed results about reductions in the frequency of binge episodes, body weight, and depressive features in two chromium groups relative to placebo group. Also, both chromium groups experienced a decrease in fasting glucose, with greater efficiency observed with chromium at higher dose.

\section{CONCLUSION}

BED is an area of profound health and societal issue. Current research concerning pharmacological therapies for BED remains in its early stages. Throughout the years, numerous guidelines and approaches have been planned for BED treatment. Unfortunately, several of the current BED pharmacotherapy research are overwhelmed by constraints for instance, inadequate sampling size, elevated placebo responses, elevated dropout rates, and uncertain correlation of results with clinical circumstances. There were not randomized controlled follow-up studies in a group of participants with binge-eating remission. Moreover, no pharmacotherapy studies have yet been released in children, teenagers, or elderly patients with BED. Lisdexamfetamine is the first medication officially allowed by the FDA to treat BED that significantly decreases binge eating frequency. Current data exhibit that some medications from different pharmacological classes may be useful in improving the primary BED-related findings. Medications that proposed for concurrent psychiatric instances (including weight, anxiety, or depression) with relative effectiveness and good tolerability for BED treatment may be upgraded to first-line therapy. 
From findings, pharmacotherapy has a great help in improvement of BED outcomes; however, till now, no drug is recommended for all patients. Subsequently, a general therapy hierarchy for BED cannot be established as the drug of choice depends deeply on the particular features of each patient regarding both efficacy and tolerability. Further pharmacotherapy research for the medications is greatly needed at a large clinical scale for additional systematic assessment. Moreover, it is desirable to investigate new drugs and drug combinations from various classes with the intervention of nonpharmacological therapy to get maximum benefits and/or to lower treatment-related side effects.

\section{FUNDING}

Nil

\section{AUTHORS CONTRIBUTIONS}

All the authors have contributed equally.

\section{CONFLICT OF INTERESTS}

The authors declare no conflict of interest.

\section{REFERENCES}

1. Association AP. Diagnostic and statistical manual of mental disorders (DSM-5 ${ }^{\circledR}$ ). $5^{\text {th }}$ ed. Arlington (VA): American Psychiatric Publishing; 2013.

2. Glisenti K, Strodl E, King R. Em-6iiarsed therapy for binge-eating disorder: a review of six cases. Clin Psychol Psychother 2018;25:842-55.

3. Walsh BT, Boudreau G. Laboratory studies of binge eating disorder. Int J Eat Disord 2003;34:S30-S8.

4. Marazziti D, Rossi L, Baroni S, Consoli G, Hollander E, CatenaDell'Osso M. Novel treatment options of binge eating disorder. Curr Med Chem 2011;18:5159-64.

5. Wilfley DE, Citrome L, Herman BK. Characteristics of binge eating disorder in relation to diagnostic criteria. Neuropsychiatr Dis Treat 2016;12:2213-23.

6. Walsh BT. Diagnostic categories for eating disorders: current status and what lies ahead. Psychiatr Clin 2019;42:1-10.

7. Udo T, Grilo CM. Prevalence and correlates of DSM-5-defined eating disorders in a nationally representative sample of US adults. Biol Psychiatry 2018;84:345-54.

8. Marzilli E, Cerniglia L, Cimino S. A narrative review of binge eating disorder in adolescence: prevalence, impact, and psychological treatment strategies. Adolesc Health Med Ther 2018;9:17-30.

9. Wonderlich SA, Gordon KH, Mitchell JE, Crosby RD, Engel SG. The validity and clinical utility of binge eating disorder. Int J Eat Disord 2009;42:687-705.

10. Culbert KM, Racine SE, Klump KL. Hormonal factors and disturbances in eating disorders. Curr Psychiatry Rep 2016;18:65.

11. Fowler N, Vo PT, Sisk CL, Klump KL. Stress as a potential moderator of ovarian hormone influences on binge eating in women. F1000Res 2019;8:222-32.

12. VR, Ganapathy D, Sasanka K. Binge-eating pattern among school students. J Crit Rev 2020;7:3242-9.

13. Erskine HE, Whiteford HA. Epidemiology of binge eating disorder. Curr Opin Psychiatry 2018;31:462-70.

14. Ziobrowski H, Brewerton TD, Duncan AE. Associations between ADHD and eating disorders in relation to comorbid psychiatric disorders in a nationally representative sample. Psychiatry Res 2018;260:53-9.

15. Kessler RC, Berglund PA, Chiu WT, Deitz AC, Hudson JI, Shahly $\mathrm{V}$, et al. The prevalence and correlates of binge eating disorder in the World Health Organization World Mental Health Surveys. Biol Psychiatry 2013;73:904-14.

16. Trompeter N, Bussey K, Hay P, Griffiths S, Murray SB, Mond J, et al. Fear of negative evaluation among eating disorders: examining the association with weight/shape concerns in adolescence. Int J Eat Disord 2019;52:261-9.

17. Dingemans A, Bruna M, Van Furth E. Binge eating disorder: a review. Int J Obes 2002;26:299-307.

18. Ramacciotti CE, Coli E, Marazziti D, Segura Garcia C, Brambilla $\mathrm{F}$, Piccinni $\mathrm{A}$, et al. Therapeutic options for binge eating disorder. Eat Weight Disord 2013;18:3-9.
19. Brambilla F, Samek L, Lovo F, Cioni L, Mellado C. Multivariate therapeutic approach to binge-eating disorder: combined nutritional, psychological and pharmacological treatment. Int Clin Psychopharmacol 2009;24:312-7.

20. McElroy SL, Guerdjikova AI, Mori N, O'Melia AM. Pharmacological management of binge eating disorder: current and emerging treatment options. Ther Clin Risk Manag 2012;8:219-41.

21. A Berner L, E Bocarsly M, G Hoebel B, M Avena N. Pharmacological interventions for binge eating: lessons from animal models, current treatments, and future directions. Curr Pharm Des 2011;17:1180-7.

22. Wang GJ, Geliebter A, Volkow ND, Telang FW, Logan J, Jayne $\mathrm{MC}$, et al. Enhanced striatal dopamine release during food stimulation in binge eating disorder. Obesity 2011;19:1601-8.

23. Tecott LH, Sun LM, Akana SF, Strack AM, Lowenstein DH, Dallman MF, et al. Eating disorder and epilepsy in mice lacking 5-HT2c serotonin receptors. Nature 1995;374:542-6.

24. Hargrave SL, Kinzig KP. Repeated gastric distension alters food intake and neuroendocrine profiles in rats. Physiol Behav 2012;105:975-81.

25. Aigner M, Treasure J, Kaye W, Kasper S, Disorders WTFoE. World federation of societies of biological psychiatry (WFSBP) guidelines for the pharmacological treatment of eating disorders. World J Biol Psychiatry 2011;12:400-43.

26. Walia V. Influence of stress and fluoxetine on immobility period of mice in tail suspension test and forced swim test. Asian J Pharm Clin Res 2016;9:302-5.

27. Greeno CG, Wing RR. A double-blind, placebo-controlled trial of the effect of fluoxetine on dietary intake in overweight women with and without the binge-eating disorder. Am J Clin Nutr 1996;64:267-73.

28. Arnold LM, McElroy SL, Hudson JI, Welge JA, Bennett AJ, Keck Jr PE. A placebo-controlled, randomized trial of fluoxetine in the treatment of the binge-eating disorder. J Clin Psychiatry 2002;63:1028-33.

29. Grilo CM, Masheb RM, Wilson GT. Efficacy of cognitivebehavioral therapy and fluoxetine for the treatment of binge eating disorder: a randomized double-blind placebo-controlled comparison. Biol Psychiatry 2005;57:301-9.

30. Devlin MJ, Goldfein JA, Petkova E, Jiang H, Raizman PS, Wolk S, et al. Cognitive behavioral therapy and fluoxetine as adjuncts to group behavioral therapy for binge eating disorder. Obes Res 2005;13:1077-88.

31. Gardiner H, Freeman C, Jesinger D, Collins S. Fluvoxamine: an open pilot study in moderately obese female patients suffering from atypical eating disorders and episodes of bingeing. Int J Obes Relat Metab Disord 1993;17:301-5.

32. Hudson JI, McElroy SL, Raymond NC, Crow S, Keck Jr PE, Carter $\mathrm{WP}$, et al. Fluvoxamine in the treatment of binge-eating disorder: a multicenter placebo-controlled, double-blind trial. Am J Psychiatry 1998;155:1756-62.

33. Pearlstein T, Spurell E, Hohlstein L, Gurney V, Read J, Fuchs C, et al. A double-blind, placebo-controlled trial of fluvoxamine in binge eating disorder: a high placebo response. Arch Womens Ment Health 2003;6:147-51.

34. McElroy SL, Casuto LS, Nelson EB, Lake KA, Soutullo CA, Keck Jr $\mathrm{PE}$, et al. Placebo-controlled trial of sertraline in the treatment of binge eating disorder. Am J Psychiatry 2000;157:1004-6.

35. Milano W, Petrella C, Capasso A. Treatment of binge eating disorder with sertraline: a randomized controlled trial. Biomed Res 2005;16:89-91.

36. Leombruni P, Pierò A, Brustolin A, Mondelli V, Levi M, Campisi $\mathrm{S}$, et al. A 12 to $24 \mathrm{w}$ pilot study of sertraline treatment in obese women binge eaters. Hum Psychopharmacol Clin Exp 2006;21:181-8.

37. Leombruni P, Piero A, Lavagnino L, Brustolin A, Campisi S, Fassino S. A randomized, double-blind trial comparing sertraline and fluoxetine 6-month treatment in obese patients with binge eating disorder. Prog Neuropsychopharmacol Biol Psychiatry 2008;32:1599-605.

38. McElroy SL, Hudson JI, Malhotra S, Welge JA, Nelson EB, Keck Jr PE. Citalopram in the treatment of binge-eating disorder: a placebo-controlled trial. J Clin Psychiatry 2003;64:807-13. 
39. Guerdjikova AI, McElroy SL, Kotwal R, Welge JA, Nelson E, Lake K, et al. High-dose escitalopram in the treatment of binge-eating disorder with obesity: a placebo-controlled monotherapy trial. Hum Psychopharmacol Clin Exp 2008;23:1-11.

40. Gibb A, Deeks ED. Vortioxetine: first global approval. Drugs 2014;74:135-45.

41. Leiser SC, Li Y, Pehrson AL, Dale E, Smagin G, Sanchez C. Serotonergic regulation of prefrontal cortical circuitries involved in cognitive processing: a review of individual 5-HT receptor mechanisms and concerted effects of 5-HT receptors exemplified by the multimodal antidepressant vortioxetine. ACS Chem Neurosci 2015;6:970-86.

42. Reiter AM, Heinze HJ, Schlagenhauf F, Deserno L. Impaired flexible reward-based decision-making in binge eating disorder: evidence from computational modeling and functional neuroimaging. Neuropsychopharmacol 2017;42:628-37.

43. Grant JE, Valle S, Cavic E, Redden SA, Chamberlain SR. A double-blind, placebo-controlled study of vortioxetine in the treatment of binge-eating disorder. Int $\mathrm{J}$ Eat Disord 2019;52:786-94.

44. Mahesh P, Jeganath S. Formulation and evaluation of venlafaxine hydrochloride sustained release matrix tablet. Asian J Pharm Clin Res 2018;11;170-4.

45. Bernardi S, Pallanti S. Successful duloxetine treatment of a binge eating disorder: a case report. J Psychopharmacol 2010;24:1269-72.

46. Lai $\mathrm{CH}$. Duloxetine related binge eating behaviors: a case report. Prog Neuropsychopharmacol Biol Psychiatry 2009;33:1581-2.

47. Leombruni P, Lavagnino L, Gastaldi F, Vasile A, Fassino S. Duloxetine in obese binge eater outpatients: preliminary results from a 12week open trial. Hum Psychopharmacol Clin Exp 2009;24:483-8.

48. Guerdjikova AI, McElroy SL, Winstanley EL, Nelson EB, Mori N, McCoy J, et al. Duloxetine in the treatment of binge eating disorder with depressive disorders: a placebo-controlled trial. Int J Eat Disord 2012;45:281-9.

49. Malhotra S, King KH, Welge JA, Brusman Lovins L, McElroy SL. Venlafaxine treatment of a binge-eating disorder associated with obesity: a series of 35 patients. J Clin Psychiatry 2002;63:802-6.

50. Silveira RO, Zanatto V, Appolinario J, Kapczinski F. An open trial of reboxetine in obese patients with binge eating disorder. Eat Weight Disord 2005;10:e93-e6.

51. Jain AK, Kaplan RA, Gadde KM, Wadden TA, Allison DB, Brewer $\mathrm{ER}$, et al. Bupropion SR vs. placebo for weight loss in obese patients with depressive symptoms. Obes Res 2002;10:1049-56.

52. Anderson JW, Greenway FL, Fujioka K, Gadde KM, McKenney J, O'neil PM. Bupropion SR enhances weight loss: a 48-week double-blind, placebo-controlled trial. Obes Res 2002;10:633-41.

53. Jefferson JW, Rush AJ, Nelson JC, VanMeter SA, Krishen A, Hampton KD, et al. Extended-release bupropion for patients with major depressive disorder presenting with symptoms of reduced energy, pleasure, and interest: findings from a randomized, double-blind, placebo-controlled study. J Clin Psychiatry 2006;67:865-73.

54. Teaima M, Hamid MMA, Shoman NA, Jasti BR, El-Nabarawi MA. Promising swellable floating bupropion tablets: formulation, in vitro/in vivo evaluation and comparative pharmacokinetic study in human volunteers. Drug Des Dev Ther 2020;14:2741.

55. Teaima MH, Hamid MMA, Shoman NA, Jasti BR, El-Nabarawi MA, Yasser M. Formulation, characterization and comparative pharmacokinetic study of bupropion floating raft system as a promising approach for treating depression. J Pharm Sci 2020;109:3451-61.

56. Calandra C, Russo RG, Luca M. Bupropion versus sertraline in the treatment of depressive patients with binge eating disorder: a retrospective cohort study. Psychiatr Q 2012;83:177-85.

57. White MA, Grilo CM. Bupropion for overweight women with binge eating disorder: randomized double-blind placebocontrolled trial. J Clin Psychiatry 2013;74:400-6.

58. Greenway FL, Fujioka K, Plodkowski RA, Mudaliar S, Guttadauria M, Erickson J, et al. Effect of naltrexone plus bupropion on weight loss in overweight and obese adults (COR-I): a multicentre, randomised, double-blind, placebocontrolled, phase 3 trial. Lancet 2010;376:595-605.

59. Guerdjikova AI, Walsh B, Shan K, Halseth AE, Dunayevich E, McElroy SL. Concurrent improvement in both binge eating and depressive symptoms with naltrexone/bupropion therapy in overweight or obese subjects with major depressive disorder in an open-label, uncontrolled study. Adv Ther 2017;34:230715.

60. Laederach Hofmann K, Graf C, Horber F, Lippuner K, Lederer S, Michel $\mathrm{R}$, et al. Imipramine and diet counseling with psychological support in the treatment of obese binge eaters: a randomized, placebocontrolled double-blind study. Int J Eat Disord 1999;26:231-44.

61. Brownley KA, Peat CM, La Via M, Bulik CM. Pharmacological approaches to the management of binge eating disorder. Drugs 2015;75:9-32.

62. Ioannides Demos LL, Piccenna L, McNeil JJ. Pharmacotherapies for obesity: past, current, and future therapies. J Obes 2010;2011:179674.

63. Chukwu J, Delanty N, Webb D, Cavalleri GL. Weight change, genetics and antiepileptic drugs. Expert Rev Clin Pharmacol 2014;7:43-51

64. Leombruni P, Lavagnino L, Fassino S. Treatment of obese patients with binge eating disorder using topiramate: a review. Neuropsychiatr Dis Treat 2009;5:385-92.

65. McElroy SL, Arnold LM, Shapira NA, Keck Jr PE, Rosenthal NR, Karim MR, et al. Topiramate in the treatment of binge eating disorder associated with obesity: a randomized, placebocontrolled trial. Am J Psychiatry 2003;160:255-61.

66. McElroy SL, Shapira NA, Arnold LM, Keck Jr PE, Rosenthal NR, Wu SC, et al. Topiramate in the long-term treatment of a bingeeating disorder associated with obesity. J Clin Psychiatry 2004;65:1463-9.

67. McElroy SL, Hudson JI, Capece JA, Beyers K, Fisher AC, Rosenthal NR, et al. Topiramate for the treatment of binge eating disorder associated with obesity: a placebo-controlled study. Biol Psychiatry 2007;61:1039-48.

68. Claudino AM, Appolinario J, Cordás T, Duchesne M, Sichieri R, Bacaltchuk J. Double-blind, randomized, placebo-controlled trial of topiramate plus cognitive-behavior therapy in bingeeating disorder. J Clin Psychiatry 2007;68:1324-32.

69. Zilberstein B, Pajecki D, De Brito ACG, Gallafrio ST, Eshkenazy $\mathrm{R}$, Andrade CG. Topiramate after adjustable gastric banding in patients with binge eating and difficulty losing weight. Obes Surg 2004;14:802-5.

70. Guerdjikova AI, Kotwal R, McElroy SL. Response of recurrent binge eating and weight gain to topiramate in patients with binge eating disorder after bariatric surgery. Obes Surg 2005;15:273-7.

71. McElroy SL, Kotwal R, Hudson JI, Nelson EB, Keck Jr PE. Zonisamide in the treatment of binge-eating disorder: an openlabel, prospective trial. J Clin Psychiatry 2004;65:50-6.

72. McElroy SL, Kotwal R, Guerdjikova AI, Welge JA, Nelson EB, Lake KA, et al. Zonisamide in the treatment of binge eating disorder with obesity: a randomized controlled trial. J Clin Psychiatry 2006;67:1897-906.

73. Ricca V, Castellini G, Sauro CL, Rotella CM, Faravelli C. Zonisamide combined with cognitive-behavioral therapy in binge eating disorder: a one-year follow-up study. Psychiatry (Edgmont) 2009;6:23-8.

74. Guerdjikova AI, McElroy SL, Welge JA, Nelson E, Keck PE, Hudson JI. Lamotrigine in the treatment of binge-eating disorder with obesity: a randomized, placebo-controlled monotherapy trial. Int Clin Psychopharmacol 2009;24:150-8.

75. Padwal RS, Majumdar SR. Drug treatments for obesity: orlistat, sibutramine, and rimonabant. Lancet 2007;369:71-7.

76. James WPT, Caterson ID, Coutinho W, Finer N, Van Gaal LF, Maggioni AP, et al. Effect of sibutramine on cardiovascular outcomes in overweight and obese subjects. N Engl J Med 2010;363:905-17.

77. Appolinario JC, Bacaltchuk J, Sichieri R, Claudino AM, Godoy Matos A, Morgan C, et al. A randomized, double-blind, placebo- 
controlled study of sibutramine in the treatment of bingeeating disorder. Arch Gen Psychiatry 2003;60:1109-16.

78. Milano W, Petrella C, Casella A, Capasso A, Carrino S, Milano L. Use of sibutramine, an inhibitor of the reuptake of serotonin and noradrenaline, in the treatment of binge eating disorder: a placebo-controlled study. Adv Ther 2005;22:25-31.

79. Wilfley DE, Crow SJ, Hudson JI, Mitchell JE, Berkowitz RI, Blakesley V, et al. Efficacy of sibutramine for the treatment of binge eating disorder: a randomized multicenter placebocontrolled double-blind study. Am J Psychiatry 2008;165:51-8.

80. Vetter ML, Faulconbridge LF, Webb VL, Wadden TA. Behavioral and pharmacologic therapies for obesity. Nat Rev Endocrinol 2010;6:578-88.

81. Coutinho W. The first decade of sibutramine and orlistat: a reappraisal of their expanding roles in the treatment of obesity and associated conditions. Arq Bras Endocrinol 2009;53:262-70.

82. Golay A, Laurent Jaccard A, Habicht F, Gachoud JP, Chabloz M, Kammer A, et al. Effect of orlistat in obese patients with binge eating disorder. Obes Res 2005;13:1701-8.

83. Grilo CM, Masheb RM, Salant SL. Cognitive-behavioral therapy guided self-help and orlistat for the treatment of binge eating disorder: a randomized, double-blind, placebo-controlled trial. Biol Psychiatry 2005;57:1193-201.

84. Grilo CM, White MA. Orlistat with behavioral weight loss for obesity with versus without binge eating disorder: randomized placebo-controlled trial at a community mental health center serving educationally and economically disadvantaged Latino/as. Behav Res Ther 2013;51:167-75.

85. Aronne LJ, Halseth AE, Burns CM, Miller S, Shen LZ. Enhanced weight loss following coadministration of pramlintide with sibutramine or phentermine in a multicenter trial. Obesity 2010;18:1739-46

86. Dalai SS, Adler S, Najarian T, Safer DL. Study protocol and rationale for a randomized double-blinded crossover trial of phentermine-topiramate ER versus placebo to treat binge eating disorder and bulimia nervosa. Contemp Clin Trials Commun 2018;64:173-8.

87. Guerdjikova AI, Williams S, Blom TJ, Mori N, McElroy SL. Combination phentermine-topiramate extended-release for the treatment of binge eating disorder: an open-label, prospective study. Innov Clin Neurosci 2018;15:17.

88. McTavish D, Heel RC. Dexenfluramine: a review of its pharmacological properties and therapeutic potential in obesity. Drugs 1992;43:713-33.

89. Stunkard A, Berkowitz R, Tanrikut C, Reiss E, Young L. dFenfluramine treatment of binge eating disorder. Am J Psychiatry 1996;153:1455-9.

90. Cheung BMY, Cheung TT, Samaranayake NR. Safety of antiobesity drugs. Ther Adv Drug Saf 2013;4:171-81.

91. Blonde L, Russell Jones D. The safety and efficacy of liraglutide with or without oral antidiabetic drug therapy in type 2 diabetes: an overview of the LEAD 1-5 studies. Diabetes Obes Metab 2009;11:26-34.

92. Pi-Sunyer X, Astrup A, Fujioka K, Greenway F, Halpern A, Krempf M, et al. A randomized, controlled trial of $3.0 \mathrm{mg}$ of liraglutide in weight management. N Engl J Med 2015;373:1122.

93. Robert SA, Rohana AG, Shah SA, Chinna K, Mohamud WNW, Kamaruddin NA. Improvement in binge eating in non-diabetic obese individuals after 3 mo of treatment with liraglutide-a pilot study. Obes Res Clin Pract 2015;9:301-4.

94. Castren ML, Jarvinen A, Laine MK, Tikkanen R. Beneficial effects of GLP-1 agonist in compulsive food-related behaviour associated with autism. Front Psychiatry 2019;10:97.

95. Dukarm CP. Bulimia nervosa and attention deficit hyperactivity disorder: a possible role for stimulant medication. J Womens Health 2005;14:345-50.

96. Swanson SA, Crow SJ, Le Grange D, Swendsen J, Merikangas KR. Prevalence and correlates of eating disorders in adolescents: results from the national comorbidity survey replication adolescent supplement. Arch Gen Psychiatry 2011;68:714-23.

97. Hudson JI, Hiripi E, Pope Jr HG, Kessler RC. The prevalence and correlates of eating disorders in the national comorbidity survey replication. Biol Psychiatry 2007;61:348-58.
98. Amodeo G, Cuomo A, Bolognesi S, Goracci A, Trusso MA, Piccinni A, et al. Pharmacotherapeutic strategies for treating binge eating disorder. Evidence from clinical trials and implications for clinical practice. Expert Opin Pharmacother 2019;20:679-90.

99. McElroy SL, Guerdjikova A, Kotwal R, Welge JA, Nelson EB, Lake $\mathrm{KA}$, et al. Atomoxetine in the treatment of binge-eating disorder: a randomized placebo-controlled trial. J Clin Psychiatry 2007;68:390-8.

100. Ward K, Citrome L. Lisdexamfetamine: chemistry, pharmacodynamics, pharmacokinetics, and clinical efficacy, safety, and tolerability in the treatment of binge eating disorder. Expert Opin Drug Metab Toxicol 2018;14:229-38.

101. Reas DL, Grilo CM. Pharmacological treatment of binge eating disorder: update review and synthesis. Expert Opin Pharmacother 2015;16:1463-78.

102. McElroy SL, Hudson JI, Mitchell JE, Wilfley D, Ferreira Cornwell MC, Gao J, et al. Efficacy and safety of lisdexamfetamine for treatment of adults with moderate to severe binge-eating disorder: a randomized clinical trial. JAMA Psychiatry 2015;72:235-46.

103. McElroy SL, Hudson J, Ferreira Cornwell MC, Radewonuk J, Whitaker T, Gasior M. Lisdexamfetamine dimesylate for adults with moderate to severe binge eating disorder: results of two pivotal phase 3 randomized controlled trials. Neuropsychopharmacol 2016;41:1251-60.

104. Hudson JI, McElroy SL, Ferreira Cornwell MC, Radewonuk J, Gasior M. Efficacy of lisdexamfetamine in adults with moderate to severe binge-eating disorder: a randomized clinical trial. JAMA Psychiatry 2017;74:903-10.

105. Gasior M, Hudson J, Quintero J, Ferreira Cornwell MC, Radewonuk J, McElroy SL. A phase 3, multicenter, open-label, 12-month extension safety and tolerability trial of lisdexamfetamine dimesylate in adults with binge eating disorder. J Clin Psychopharmacol 2017;37:315-22.

106. McElroy SL, Hudson JI, Gasior M, Herman BK, Radewonuk J, Wilfley D, et al. Time course of the effects of lisdexamfetamine dimesylate in two phase 3, randomized, double-blind, placebo-controlled trials in adults with binge-eating disorder. Int J Eat Disord 2017;50:884-92.

107. Davis C, Levitan RD, Kaplan AS, Carter J, Reid C, Curtis C, et al. Dopamine transporter gene (DAT1) associated with appetite suppression to methylphenidate in a case-control study of binge eating disorder. Neuropsychopharmacol 2007;32:2199206.

108. Davis C, Levitan RD, Kaplan AS, Carter Major JC, Kennedy JL. Sex differences in subjective and objective responses to a stimulant medication (methylphenidate): comparisons between overweight/obese adults with and without the binge-eating disorder. Int J Eat Disord 2016;49:473-81.

109. Quilty LC, Allen TA, Davis C, Knyahnytska Y, Kaplan AS. A randomized comparison of long acting methylphenidate and cognitive behavioral therapy in the treatment of binge eating disorder. Psychiatry Res 2019;273:467-74.

110. Gearhardt AN, Yokum S, Orr PT, Stice E, Corbin WR, Brownell KD. Neural correlates of food addiction. Arch Gen Psychiatry 2011;68:808-16.

111. N Gearhardt A, A White M, N Potenza M. Binge eating disorder and food addiction. Curr Drug Abuse Rev 2011;4:201-7.

112. Schreiber LR, Odlaug BL, Grant JE. The overlap between binge eating disorder and substance use disorders: diagnosis and neurobiology. J Behav Addict 2013;2:191-8.

113. Broft AI, Spanos A, Corwin RL, Mayer L, Steinglass J, Devlin MJ, et al. Baclofen for binge eating: an open-label trial. Int J Eat Disord 2007;40:687-91.

114. Corwin RL, Boan J, Peters KF, Ulbrecht JS. Baclofen reduces binge eating in a double-blind, placebo-controlled, crossover study. Behav Pharmacol 2012;23:616-25.

115. de Beaurepaire R, Joussaume B, Rapp A, Jaury P. Treatment of binge eating disorder with high-dose baclofen: a case series. J Clin Psychopharmacol 2015;35:357-9.

116. Giuliano C, Cottone P. The role of the opioid system in binge eating disorder. CNS Spectrums 2015;20:537-45. 
117. Marrazzi M, Markham K, Kinzie J, Luby E. Binge eating disorder: response to naltrexone. Int $\mathrm{J}$ Obes Relat Metab Disord 1995;19:143-5.

118. Raingeard I, Courtet P, Renard E, Bringer J. Naltrexone improves blood glucose control in type 1 diabetic women with severe and chronic eating disorders. Diabetes Care 2004;27:847-8.

119. Marrazzi M, Bacon J, Kinzie J, Luby E. Naltrexone use in treatment of anorexia nervosa and bulimia nervosa. Int Clin Psychopharmacol 1995;10:163-72.

120. Jonas JM, Gold MS. Treatment of antidepressant-resistant bulimia with naltrexone. Int J Psychiatr Med 1987;16:305-9.

121. Jonas JM, Gold MS. The use of opiate antagonists in treating bulimia: a study of low-dose versus high-dose naltrexone. Psychiatry Res 1988;24:195-9.

122. Greenway FL, Dunayevich E, Tollefson G, Erickson J, Guttadauria M, Fujioka K, et al. Comparison of combined bupropion and naltrexone therapy for obesity with monotherapy and placebo. J Clin Endocrinol Metab 2009;94:4898-906.

123. Alger SA, Schwalberg MD, Bigaouette JM, Michalek AV, Howard LJ. Effect of a tricyclic antidepressant and opiate antagonist on binge-eating behavior in norm weight bulimic and obese, binge-eating subjects. Am J Clin Nutr 1991;53:865-71.

124. Avena NM, Murray S, Gold MS. The next generation of obesity treatments: beyond suppressing appetite. Front Psychol 2013;4:721.

125. Gold MS, Avena NM. Animal models lead the way to further understanding food addiction as well as providing evidence that drugs used successfully in addictions can be successful in treating overeating. Biol Psychiatry 2013;74:e11.

126. Avena NM, Bocarsly ME, Murray S, Gold MS. Effects of baclofen and naltrexone, alone and in combination, on the consumption of palatable food in male rats. Exp Clin Psychopharmacol 2014;22:460-7.

127. Neumeister A, Winkler A, Wober Bingol C. Addition of naltrexone to fluoxetine in the treatment of binge eating disorder. Am J Psychiatry 1999;156:797.

128. Meyer F. Alleviation of both binge eating and sexual dysfunction with naltrexone. J Clin Psychopharmacol 2008;28:722-3.

129. McElroy SL, Guerdjikova AI, Mori N, Keck PE. Psychopharmacologic treatment of eating disorders: emerging findings. Curr Psychiatry Rep 2015;17:35.

130. Spanagel R. Alcoholism: a systems approach from molecular physiology to addictive behavior. Physiol Rev 2009;89:649-705.

131. Nealey KA, Smith AW, Davis SM, Smith DG, Walker BM. к-opioid receptors are implicated in the increased potency of intraaccumbens nalmefene in ethanol-dependent rats. Neuropharmacology 2011;61:35-42.

132. Marazziti D, Piccinni A, Baroni S, Dell'Osso L. Effectiveness of nalmefene in binge eating disorder: a case report. J Clin Psychopharmacol 2016;36:103-4.
133. Hillemacher T, Heberlein A, Muschler MA, Bleich S, Frieling H. Opioid modulators for alcohol dependence. Expert Opin Investig Drugs 2011;20:1073-86.

134. McElroy SL, Guerdjikova AI, Blom TJ, Crow SJ, Memisoglu A, Silverman BL, et al. A placebocontrolled pilot study of the novel opioid receptor antagonist ALKS in binge eating disorder. Int J Eat Disord 2013;46:239-45.

135. Blednov YA, Adron Harris R. Metabotropic glutamate receptor 5 (mGluR5) regulation of ethanol sedation, dependence and consumption: relationship to acamprosate actions. Int J Neuropsychopharmacol 2008;11:775-93.

136. Olive MF, Cleva RM, Kalivas PW, Malcolm RJ. Glutamatergic medications for the treatment of drug and behavioral addictions. Pharmacol Biochem Behav 2012;100:801-10.

137. McElroy SL, Guerdjikova AI, Winstanley EL, O'Melia AM, Mori N, McCoy J, et al. Acamprosate in the treatment of binge eating disorder: a placebo-controlled trial. Int J Eat Disord 2011;44:81-90.

138. Hermanussen M, Tresguerres J. A new anti-obesity drug treatment: first clinical evidence that, antagonizing glutamategated $\mathrm{Ca} 2+$ ion channels with memantine normalises bingeeating disorders. Econ Hum Biol 2005;3:329-37.

139. Brennan BP, Roberts JL, Fogarty KV, Reynolds KA, Jonas JM, Hudson JI. Memantine in the treatment of binge eating disorder: An openlabel, prospective trial. Int J Eat Disord 2008;41:520-6.

140. Zaharna M, Dimitriu A, Guilleminault C. Expert opinion on pharmacotherapy of narcolepsy. Expert Opin Pharmacother 2010;11:1633-45

141. Pardi D, Black J. $\gamma$-hydroxybutyrate/sodium oxybate. CNS Drugs 2006;20:993-1018.

142. McElroy SL, Guerdjikova AI, Winstanley EL, O'melia AM, Mori N, Keck Jr PE, et al. Sodium oxybate in the treatment of binge eating disorder: an openlabel, prospective s tudy. Int J Eat Disord 2011;44:262-8.

143. Davis CM, Vincent JB. Chromium oligopeptide activates insulin receptor tyrosine kinase activity. Biochemistry 1997;36:4382-5.

144. Piotrowska A, Mlyniec K, Siwek A, Dybala M, Opoka W, Poleszak E, et al. Antidepressant-like effect of chromium chloride in the mouse forced swim test: involvement of glutamatergic and serotonergic receptors. Pharmacol Rep 2008;60:991-5.

145. Gerozissis K. Brain insulin, energy and glucose homeostasis; genes, environment and metabolic pathologies. Eur J Pharmacol 2008;585:38-49.

146. Brownley KA, Von Holle A, Hamer RM, La Via M, Bulik CM. A double-blind, randomized pilot trial of chromium picolinate for binge eating disorder: results of the binge eating and chromium (BEACh) study. J Psychosom Res 2013;75:36-42. 